\title{
Identifikasi Karakteristik Habitat Bertelur dan Uji Penetasan semi alami (in-situ) Telur Burung Mamoa (Eulipoa wallecei) di Desa Simau Kecamatan Galela Kabupaten Halmahera Utara
}

\author{
Identification of Egg-laying Habitat Characteristics and Hatching Test of semi-natural (in- \\ situ) Mamoa Bird Eggs (Eulipoa wallecei) in Simau Village, Galela District, North \\ Halmahera Regency
}

\section{B. A. Sadjab*, R. Kondolembang, Sunarno, O.F.W. Tutupary, dan B. R. Toisuta}

Fakultas Ilmu Alam dan Teknologi Rekayasa, Universitas Halmahera Kampus UNIERA Kompleks GMIH, Wari Ino Tobelo, Halmahera Utara, 97762

Corresponding email: bayu0604@gmail.com

\begin{abstract}
Research aimed in identifying the characteristics of the Mamoa (Eulipoa wallecei) egg-laying habitat and seminatural (in-situ) egg hatching tests has been conducted in Simau Village, Galale District, North Halmahera Regency. Research by observation technique was carried out directly in the field precisely at the location of the Mamoa bird laying habitat (Eulipoa wallecei) located in Simau Village, to determine the daily variation of the microclimate hole in the sand as a habitat for the Mamoa bird laying eggs, and research in the laboratory to test the content metals in the sand so that the thermal conductivity is known, and semi-natural (in-situ) hatching tests are carried out at depths of 40,60 and $80 \mathrm{~cm}$ to determine the percentage of hatchability, incubation time and mortality. The results showed that the characteristics of the Mamoa egg-laying habitat in Simau Village, Galela sub-district, North Halmahera Regency, which were studied based on microclimate studies showed fluctuations in temperature and humidity which varied based on depth and time of observation, where the average maximum temperature occurred during the daytime and the minimum temperature occurred when at night, while the lowest humidity occured during the daytime and the highest value occured at night. The largest content of sand as a habitat for Mamoa birds laying in Simau Village is the Fe (Iron) element of 58.59\% with high thermal conductivity. There was a difference in hatchability and length of incubation of hatching eggs in-situ (seminatural) at a depth of $40 \mathrm{~cm}, 60 \mathrm{~cm}$ and $80 \mathrm{~cm}$, where the greatest hatchability that reaches a percentage of $100 \%$ was at a depth of $80 \mathrm{~cm}$ with an average incubation time the fastest around $63.75 \pm 2.25$ days.
\end{abstract}

Key words : Mamoa bird (Eulipoa wallecei), eeg laying habitat characteristics, hatching test

\begin{abstract}
ABSTRAK
Penelitian yang bertujuan untuk mengidentifikasi karakteristik habitat bertelur burung Mamoa (Eulipoa wallecei) dan uji penetasan telur secara semi alami (in-situ) telah dilakukan di Desa Simau Kecamatan Galela Halmahera Utara. Penelitian dengan teknik observasi atau pengamatan dilakukan secara langsung di lapangan tepatnya di lokasi habitat bertelur burung Mamoa (Eulipoa wallecei) yang berada di Desa Simau, untuk mengetahui variasi harian iklim mikro lubang pada pasir sebagai habitat bertelur burung Mamoa, dan penelitian di laboratorium untuk menguji kandungan logam dalam pasir sehingga diketahui tingkat konduktivitas termalnya, serta dilakukan uji penetasan secara semi alami (in-situ) pada kedalaman 40, 60 dan $80 \mathrm{~cm}$ untuk mengetahui presentase daya tetas, waktu inkubasi dan mortalitasnya. Hasil penelitian menunjukkan karakteristik habitat bertelur burung Mamoa di Desa Simau kecamatan Galela Kabupaten Halmahera utara yang dikaji berdasarkan kajian mikroklimat menujukkan fluktuasi suhu dan kembaban yang bervariasi berdasarkan kedalaman dan waktu pengamatan, dimana rata-rata suhu maksimum terjadi pada saat siang hari dan suhu minimumnya terjadi saat malam hari, sementara kelembaban terendah terjadi saat siang hari dan nilai tertingginya terjadi pada saat malam hari. Kadungan terbesar dalam pasir sebagai habitat bertelur burung Mamoa Desa Simau adalah unsur Fe (Besi) sebesar 58,59\% dengan sifat konduktivitas termal yang tinggi. Terdapat perbedaan pada daya tetas dan lamanya inkubasi penetasan telur secara in-situ (semi alami) pada kedalaman $40 \mathrm{~cm}, 60 \mathrm{~cm}$ dan $80 \mathrm{~cm}$, dimana daya tetas terbesar yang mencapai presentase $100 \%$ berada pada kedalaman tanam $80 \mathrm{~cm}$ dengan rata-rata waktu inkubasi yang paling cepat sekitar $63,75 \pm 2,25$ hari.
\end{abstract}

Kata kunci : Burung Mamoa (Eulipoa wallecei), karaktersitik habitat bertelur, uji penetasan 


\section{PENDAHULUAN}

Maluku Utara terutama Pulau Halmahera merupakan salah satu daerah yang menjadi prioritas konservasi, yaitu konservasi untuk biodiversitas. Pulau ini merupakan pulau terbesar di Maluku utara yang menjadi habitat dari 210 jenis burung, dimana terdapat 24 diantaranya burung endemik kepulauan Maluku (Sujatnika et al., 1995).

Megapoda merupakan satu diantara banyak genus burung endemik yang ada di Maluku Utara. Berdasarkan data dari 22 spesies Megapoda terdapat tiga yang berada di Maluku Utara yakni Eulipoa wallacei (Burung Gosong Maluku atau Mamoa) yang masuk dalam jenis Megapodius wallacei, Gosong Sula yang masuk dalam jenis Megapodius bernsteinii, dan terdapat juga jenis Megapodius freycinent (Gosong Kelam) (Sujatnika et al, 1995). Dari data penyebaran burung Mamoa (Eulipoa wallacei), habitat terbesar yang berada pada kepulauan Maluku Utara berada di Kecamatan Galela dengan luas kurang lebih mencapai $3.91 \mathrm{~km}^{2}$ (Gambar 1).

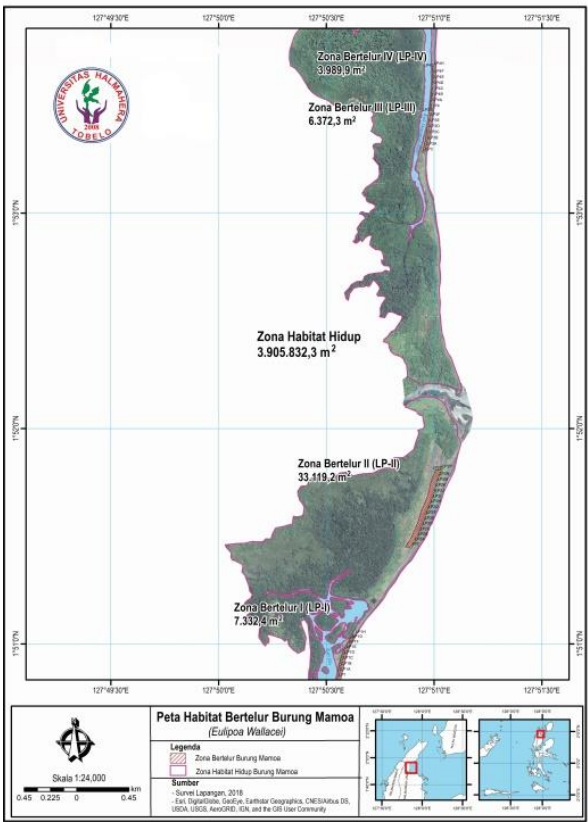

Gambar 1. Lokasi Habitat Burung Mamoa Kecamatan Galela

Habitat bertelur burung Mamoa (Eulipoa wallacei) adalah pantai dengan hamparan pasir hitam yang terbuka (Gilliant, 1998). Karena dalam perkembangbiakannya burung Mamoa tidak melakukan pengeraman telurnya secara langsung, seperti pada jenis unggas umumnya. Burung Mamoa (Eulipoa wallacei) memanfaatkan media pasir untuk membantu proses pengeraman, caranya adalah dengan membenamkan telur mamoa kedalam pasir yang secara alamiah akan mendapatkan panas melalui bantuan sumber panas dari matahari serta panas dari dalam bumi, sehingga membantu proses pengeraman telurnya (Jones, 1995). Oleh karena itu lokasi atau habitat bertelur dari burung Mamoa adalah komponen paling penting dalam menjaga kelestarian dari burung endemik ini sehingga tidak punah.

Masalah utama yang dihadapi dalam usaha pelestarian burung Mamoa ini adalah turunnya populasi yang secara drastis akibat adanya ekspoitasi yang berlebihan dan masif terhadap telurnya, penurunan kualitas dari habitatnya karena masalah degradasi serta adanya perubahan lingkungan atau fragmentasi yang terjadi pada habitat bertelur burung Mamoa (Eulipoa wallacei) (Sapsuha et al., 2017).

Berdasarkan latar belakang diatas maka penelitian ini dilakukan dengan tujuan untuk mengetahui karakteristik dari habitat bertelur burung Mamoa yang berada di Desa Simau Kecamatan Galela secara mikro, sehingga dapat menghasilkan gambaran yang secara ilmiah dapat menjadi dasar untuk melakukan konservasi, terutama dalam aspek perkembangbiankan telur burung Mamoa yang memanfaatkan media pasir dalam proses pengeramannya.

\section{MATERI DAN METODE}

Penelitian dilakukan pada lokasi habitat bertelur yang terletak di Desa Simau kecamatan Galela yang merupakan salah satu lokasi bertelur terbesar burung Mamoa yang berada di kecamtan Galela Kabupaten Halmahera Utara, dengan luas kurang lebih 7.332,4 $\mathrm{m}^{2}$ (Gambar 2). Penelitian dilakukan selama 3 bulan yang dimulai pada bulan Mei 2019 sampai dengan Juli 2019 yang terdiri dari penelitian di lokasi habitat bertelur, Laboratorium Universitas Halmahera dan Laboratorium Universitas Negeri Malang. Tahapan penelitian dimulai dengan melakukan pengamatan secara langsung di lokasi habitat bertelur melalui proses eksplorasi terhadap iklim mikro lubang penetasan, kemudian dilanjutkan dengan pengambilan sampel pasir, serta melakukan uji penetasan secara insitu (semi alami) di sekitar lokasi bertelur burung Mamoa yang berada di desa Simau Galela. 


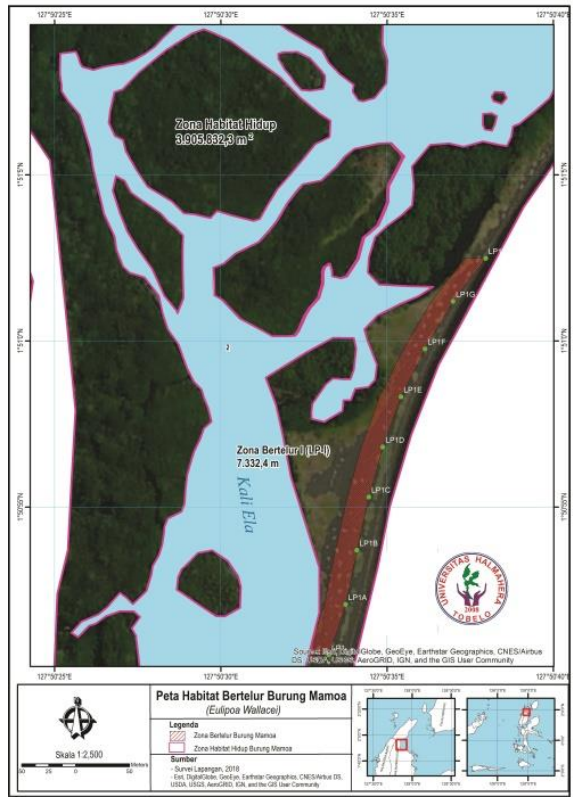

Gambar 2. Lokasi habitat burung Mamoa di Desa Simau Galela

\section{Pengamatan Variasi Harian Iklim Mikro Lubang Bertelur}

Proses ini dilakukan secara langsung di lokasi bertelur burung Mamoa yang berada di desa Simau Galela, yaitu dengan melakukan pengamatan dan pengukuran iklim mikro lubang bertelur burung Mamoa secara periodik dalam 24 jam terbagi menjadi 4 waktu pengamatan, dimana masing-masing pengamatan dilakukan pada 2 waktu berbeda yaitu pada pagi hari pukul 07.00 dan 09.00, siang hari pukul 11.00 dan 13.00 , sore hari 15.00 dan 17.00 dan malam hari 19.00 dan 21.00. Pengamatan dilakukan terhadap 4 lubang yang dibuat dengan variasi kedalaman 40, 60,70 dan $80 \mathrm{~cm}$, hal ini didasarkan pada ratarata lubang alamiah yang dibuat oleh burung Mamoa dalam menanam telurnya baik itu pada saat bulan terang maupun bulan gelap yakni sekitar 40 - $100 \mathrm{~cm}$. Menurut Sjafani (2015), kedalaman lubang selain dipengaruhi oleh temperatur dan diameter lubang juga dipengaruhi oleh pengaruh bulan gelap dan bulan terang, dimana saat bulan terang kedalaman lubang penetasan alamiah yang dibuat oleh burung Mamoa akan makin dalam. Variabel yang diamati pada proses ini adalah mikroklimat yang terdiri dari perubahan variasi harian tempertaur dan kelembaban lubang bertelur.

\section{Karakteristik Pasir Habitat Bertelur}

Metode yang digunakan adalah metode pengujian, yaitu dengan melakukan pengambilan sampel pasir yang berada di lokasi habitat bertelur burung Mamoa, proses selanjutnya adalah sterilisasi sampel pasir dan penggerusan, kemudian dilakukan uji laboratoium untuk mendapatkan karakteristik dari pasir tersebut menggunakan X-Ray Fluorescence (XRF).

\section{Penetasan}

Penetasan dilakukan dengan menggunakan metode eksperimen, yaitu melalui proses semi alami atau in-situ, dimana telur ditanam di dalam pasir dengan kedalaman $40 \mathrm{~cm}$, $60 \mathrm{~cm}$ dan $80 \mathrm{~cm}$ pada luasan yang telah ditentukan, yang sebelumnya dibatasi oleh kotak sarang. sebanyak 24 telur yang ditanam pada setiap kedalaman tersebut, telur yang ditetaskan dalam penelitian ini adalah telur yang berasal dari habitat alaminya dengan pengaturan jarak tanam antara $20-25 \mathrm{~cm}$, dan posisi telur yang benar yaitu secara vertikal dengan bagian yang lebih runcing berada dibawahnya (Lembang et al, 2018).

\section{HASIL DAN PEMBAHASAN}

\section{Variasi Harian Iklim Mikro Lubang Habitat Bertelur}

Hasil pengamatan terhadap 4 lubang yang telah dibuat menunjukkan variasi temperatur harian (Tabel 1). Hasil pengamatan menunjukkan rataan temperatur minimum lubang pada kedalaman $40 \mathrm{~cm}$ sebesar $31,88{ }^{\circ} \mathrm{C}$ yang terjadi saat malam hari dan rataan kelembaban minimum sebesar $33 \%$ yang terjadi saat siang hari, sementara rataan temperatur maksimum lubang pada kedalaman $40 \mathrm{~cm}$ sebesar $42,95{ }^{\circ} \mathrm{C}$ siang hari dan kelembaban maksimumnya sebesar 85,5 \% saat malam hari. Pada lubang dengan kedalaman $60 \mathrm{~cm}$ rataan temperatur minimum juga terjadi pada malam hari sebesar $31.45{ }^{\circ} \mathrm{C}$ dan rataan kelembaban minumumnya terjadi saat siang sebesar $39,5 \%$, sementara rataan temperatur maksimumnya terjadi saat siang hari sebesar $41,38{ }^{\circ} \mathrm{C}$ dan kelembaban maksimumnya saat malam hari sebesar $86 \%$. Lubang pada kedalaman $70 \mathrm{~cm}$ menunjukkan hal yang sama dimana temperatur minimum terjadi saat malam hari sebesar $31,33{ }^{\circ} \mathrm{C}$ dan kelembaban minimumnya sebesar $40 \%$ saat siang hari, sementara rataan temperatur maksimumnya terjadi pada siang hari sebesar $41,5^{\circ} \mathrm{C}$ dan rataan kelembaban maksimumnya sebesar $84,5 \%$ yang terjadi saat malam hari. Hal lain ditunjukkkan pada lubang dengan kedalaman $80 \mathrm{~cm}$ dimana rataan temperatur minimum justru terjadi saat 
Tabel 1. Variasi Harian iklim Mikro Lubang Habitat Bertelur Burung Mamoa di Desa Simau Kecamatan Galela Kabupaten Halmahera Utara

\begin{tabular}{|c|c|c|c|c|c|c|c|}
\hline \multirow{2}{*}{$\begin{array}{c}\text { Kelompok } \\
\text { Waktu }\end{array}$} & \multirow{2}{*}{$\begin{array}{c}\text { Waktu } \\
\text { Pengamatan }\end{array}$} & \multirow{2}{*}{ Kedalaman } & \multicolumn{4}{|c|}{ Suhu $\left({ }^{\circ} \mathrm{C}\right)$} & \multirow{2}{*}{$\begin{array}{c}\text { Kelembaban } \\
(\%)\end{array}$} \\
\hline & & & I & II & III & Rataan & \\
\hline \multirow{6}{*}{ Pagi hari } & \multirow{3}{*}{07.00} & 40 & 30.9 & 31 & 31 & 30.97 & 91 \\
\hline & & 60 & 30.6 & 31.7 & 32 & 31.43 & 91 \\
\hline & & 80 & 29.5 & 31.3 & 31.8 & 30.87 & 90 \\
\hline & \multirow{3}{*}{09.00} & 40 & 34.2 & 34.9 & 34.1 & 34.40 & 49 \\
\hline & & 60 & 33.2 & 33.9 & 34.1 & 33.73 & 50 \\
\hline & & 80 & 32.7 & 32.7 & 32.7 & 32.70 & 38 \\
\hline \multirow{6}{*}{ Siang hari } & \multirow{3}{*}{11.00} & 40 & 42.6 & 42.8 & 42.5 & 42.63 & 38 \\
\hline & & 60 & 40.6 & 41.3 & 41.3 & 41.07 & 43 \\
\hline & & 80 & 39.6 & 39.2 & 38.9 & 39.23 & 48 \\
\hline & \multirow{3}{*}{13.00} & 40 & 43.9 & 43 & 42.9 & 43.27 & 28 \\
\hline & & 60 & 42 & 41.9 & 41.2 & 41.70 & 36 \\
\hline & & 80 & 40 & 39.8 & 39.5 & 39.77 & 38 \\
\hline \multirow{6}{*}{ Sore hari } & \multirow{3}{*}{15.00} & 40 & 41 & 40.7 & 39.5 & 40.40 & 40 \\
\hline & & 60 & 38.5 & 38 & 37.2 & 37.90 & 46 \\
\hline & & 80 & 39.2 & 39 & 38.5 & 38.90 & 49 \\
\hline & \multirow{3}{*}{17.00} & 40 & 32 & 32 & 32 & 32.00 & 65 \\
\hline & & 60 & 32.5 & 32.6 & 32.6 & 32.57 & 66 \\
\hline & & 80 & 33.8 & 34.3 & 34.4 & 34.17 & 67 \\
\hline \multirow{6}{*}{$\begin{array}{l}\text { Malam } \\
\text { hari }\end{array}$} & \multirow{3}{*}{19.00} & 40 & 31.7 & 32.6 & 33.4 & 32.57 & 82 \\
\hline & & 60 & 30.1 & 31.7 & 32 & 31.27 & 83 \\
\hline & & 80 & 32.1 & 32.3 & 32.5 & 32.30 & 83 \\
\hline & \multirow{3}{*}{21.00} & 40 & 30.1 & 31.5 & 32 & 31.20 & 89 \\
\hline & & 60 & 31.1 & 31.7 & 32.1 & 31.63 & 89 \\
\hline & & 80 & 30.7 & 31.2 & 31.9 & 31.27 & 90 \\
\hline
\end{tabular}

pagi hari sebesar $31,78{ }^{\circ} \mathrm{C}$ dengan kelembaban minimumnya terjadi siang hari sebesar $43 \%$, sementara rataan temperatur maksimumnya tetap terjadi saat siang hari sebesar $39,5{ }^{\circ} \mathrm{C}$ dan rataan kelembaban maksimumnya sebesar $86,5 \%$ terjadi saat malam hari.

\section{Karakteristik Pasir Habitat Bertelur Burung Mamoa}

Hasil pengamatan menggunakan X-Ray Fluorescence (XRF) terhadap kadar logam yang terkandung dalam pasir sebagai habitat bertelur burung mamoa yang berada di Desa Simau kecamatan Galela (Gambar 3), menunjukkan bahwa pasir yang ada di Desa Simau memiliki kandungan logam yang banyak dengan komposisi kandungan yang bervariasi, antara lain unsur $\mathrm{Al}$ (Aluminium), Si (Silika), $\mathrm{P}$ (Pospor), $\mathrm{K}$ (Kalium), Ca (Kalsium), Ti (Titanium), V (Vanadium), Cr (Krom), Mn (Mangan), $\mathrm{Fe}$ (Besi), $\quad \mathrm{Cu}$ (Tembaga), $\mathrm{Zn} \quad$ (Seng), $\mathrm{Eu}$ (Europium), dan unsur Re (Rhenium), dimana kandungan terkecil yaitu unsur Zn (seng) dengan komposisi sebesar $0.06 \%$ dan kandungan logam terbesar yaitu unsur $\mathrm{Fe}$ atau besi dengan komposisi sebesar 58,59\%.

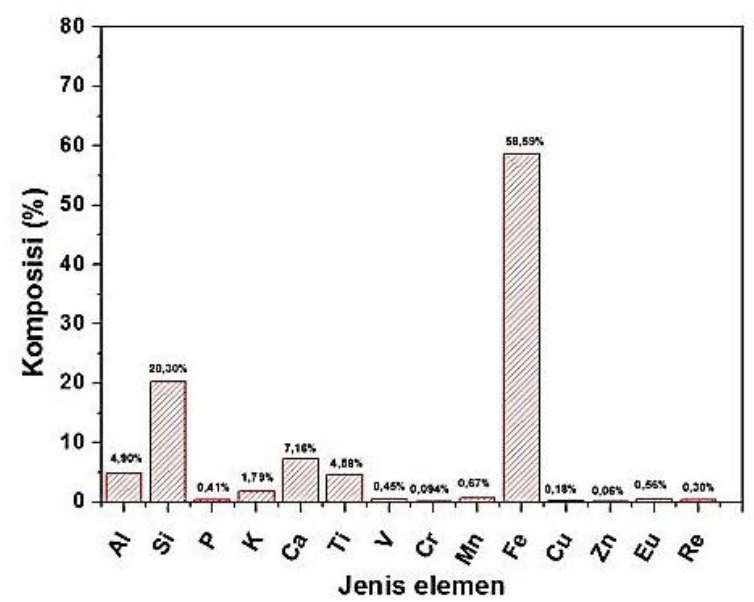

Gambar 3. Kandungan Unsur logam dalam Pasir lokasi habitat Bertelur Burung Mamoa di Desa Simau Kecamatan Galela menggunakan (XRF)

Tinggingya kandungan $\mathrm{Fe}$ juga dapat dilihat berdasarkan hasil spektrum dari 
fluorescence atau hamburan (Gambar 4). Fe merupakan salah satu logam dengan nilai konduktivitas termal yang tinggi yaitu sebasar 73 W/M ${ }^{\circ} \mathrm{C}$ (Pertiwi et al, 2015), konduktivitas termal $(\mathrm{K})$ merupakan besaran intensif bahan yang menunjukkan kemampuan bahan tersebut menghantarkan panas, atau bisa dikatakan sebagai sifat dari suatu zat yang mengalami perpindahan panas yang tinggi. Tingginya konduktivitas termal dari unsur $\mathrm{Fe}$ yang terkandung dalam pasir akan sangat berpengaruh terhadap variasi temperatur dan kelembaban dari pasir itu sendiri berdasarkan kedalamannya.

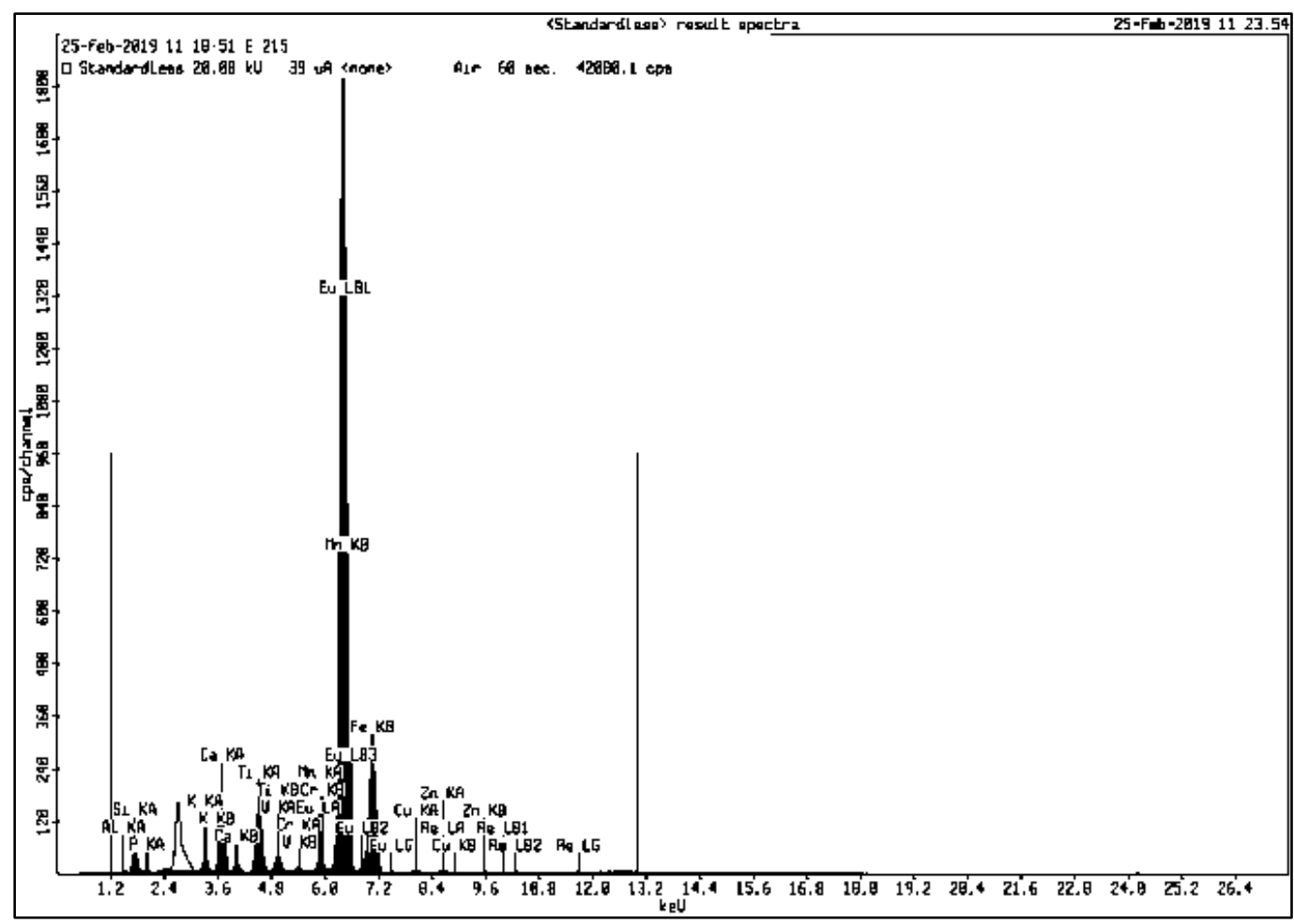

Gambar 4. Spektrum Flourescence kandungan dalam Pasir lokasi Habitat Bertelur Burung Mamoa di Desa Simau Kecamatan Galela

\section{Penetasan}

Hasil penelitian (Tabel 2) menunjukkan perbedaan daya tetas antara penanaman yang dilakukan pada variasi jarak $40 \mathrm{~cm}, 60 \mathrm{~cm}$, dan $80 \mathrm{~cm}$. Berdasarkan hasil penelitian daya tetas terbesar berada pada kedalaman $80 \mathrm{~cm}$ dengan presentase sebesar $100 \%$, kemudian pada kedalaman $60 \mathrm{~cm}$ dengan presentase daya tetas sebesar $95,83 \%$ dan yang paling rendah berada pada kedalaman $40 \mathrm{~cm}$ dengan presentase daya tetas sebesar $41,66 \%$. perbedaan ini dipengaruhi oleh adanya fluktuasi suhu dan kelembaban yang diinterpretasikan dipengaruhi oleh cuaca dan kandungan $\mathrm{Fe}$ yang tinggi pada pasir lokasi habitat bertelur burung Mamoa (Eulipoa Wallecei), Dimana temperatur dan kelembaban sangat berperan penting terhadap perkembangan embrio, data tetas telur dan pertumbuhan anakan burung (Decuypere, 1992).

Tabel 2. Pengujian penetasan secara semi alami (in-situ) pada kedalaman berbeda

\begin{tabular}{cllll}
\hline \multirow{2}{*}{ No } & \multicolumn{1}{c}{ Pengamatan } & \multicolumn{3}{c}{ Kedalaman } \\
\cline { 3 - 5 } & & \multicolumn{1}{c}{$40 \mathrm{~cm}$} & \multicolumn{1}{c}{$60 \mathrm{~cm}$} & \multicolumn{1}{c}{$80 \mathrm{~cm}$} \\
\hline 1 & Daya Tetas (\%) & 41,66 & 95,83 & 100 \\
2 & Lama Inkubasi (hari) & $73,1 \pm 2,27$ & $70,2 \pm 1,64$ & $67,3 \pm 1,63$ \\
3 & Temperatur $\left({ }^{\circ} \mathrm{C}\right)$ & $35,93 \pm 1,92$ & $35,16 \pm 1,43$ & $34,9 \pm 1,24$ \\
4 & Kelembaban (\%) & $60,13 \pm 4,81$ & $63 \pm 3,74$ & $63,75 \pm 2,25$ \\
5 & Mortalitas (\%) & 58,33 & 4,17 & 0 \\
\hline
\end{tabular}


Selain adanya perbedaan daya tetas hasil penelitian yang dilakukan secara semi alami (insitu) yang langsung dilakukan pada lokasi habitat bertelur Desa Simau Kecamtan Galela Halmahera Utara dengan variasi kedalaman tanam $40 \mathrm{~cm}, 60$ $\mathrm{cm}$, dan $80 \mathrm{~cm}$ ini juga menunjukkan variasi lamanya waktu inkubasi. Berdasarkan hasil penelitian (tabel 2) terlihat lamanya inkubasi telur burung mamoa pada kedalaman $40 \mathrm{~cm}$ ratarata $73,1 \pm 2,27$ hari, sementara itu pada kedalaman $60 \mathrm{~cm}$ lamanya waktu inkubasi ratarata 70,2 $\pm 1,64$ hari, dan pada kedalaman $80 \mathrm{~cm}$ membutuhkan waktu sekitar 67,3 $\pm 1,63$ hari. Lamanya inkubasi pada jenis megapoda secara umum memiliki variasi. Menurut Sumangando, 2002 lama inkubasi pada telur burung mamoa sampai menetas yang ditetaskan secara buatan bervariasi antara 54-63 hari dengan temperatur sekitar 33,90-34 ${ }^{\circ} \mathrm{C}$ dan kelembaban $70-70,6 \%$. Sementara itu jenis megapoda lain yang menetas secara alamiah di alam juga bervariasi sesuai spesiesnya, seperti Megapodius eremita yang mencapai 42-70 hari (Jones et al., 1995). Daya tetas akan berbanding terbalik dengan tingkat mortalitas dari proses penetasan telur burung mamoa dimana tinkgat mortalitas tertinggi terjadi pada telur yang ditanam pada kedalaman $40 \mathrm{~cm}$ sementara itu tingkat mortalitas terendah terjadi pada telur yang ditanam dengan kedalaman 80 $\mathrm{cm}$.

\section{KESIMPULAN}

Karakteristik habitat bertelur burung mamoa di Desa Simau kecamatan Galela Kabupaten Halmahera utara yang dikaji berdasarkan kajian mikroklimat menujukkan fluktuasi suhu dan kembaban yang bervariasi berdasarkan kedalaman dan waktu pengamatan, dimana rata-rata suhu maksimum terjadi pada saat siang hari dan suhu minimumnya terjadi saat malam hari, sementara kelembaban terendah terjadi saat siang hari dan nilai tertingginya terjadi pada saat malam hari. Kadungan terbesar dalam pasir sebagai habitat bertelur burung Mamoa Desa Simau adalah unsur Fe (Besi) sebesar 58,59 \% dengan sifat konduktivitas termal yang tinggi. Terdapat perbedaan pada daya tetas dan lamanya inkubasi penetasan telur secara in-situ (semi alami) pada kedalaman 40 $\mathrm{cm}, 60 \mathrm{~cm}$ dan $80 \mathrm{~cm}$, dimana daya tetas terbesar yang mencapai presentase $100 \%$ berada pada kedalaman tanam $80 \mathrm{~cm}$ dengan rata-rata waktu inkubasi yang paling cepat sekitar 63,75 $\pm 2,25$ hari.

\section{SARAN}

Penelitian lebih lanjut tentang karakteristik habitat bertelur burung Mamoa (Eulipoa wallecei) perlu dilakukan untuk beberapa aspek kajian agar didapatkan hasil penelitian yang menyeluruh sehingga informasinya menjadi lengkap dan dapat dijadikan referensi ilmiah dalam menjaga populasi dan kelestarian habitat burung endemik ini.

\section{DAFTAR PUSTAKA}

Decuypere, E., and H. Michels. 1992. Incubation temperature as a management tool: a review. World's Poultry Science Journal. 48 (1): 28-38.

Gilliant, B. 1998. Bird of The Spice Island Molucan Megapoda Conservation Project. University of Sussex.

Jones, D. N., R.W.J. Dekker, and C.S. Roselaar. 1995. Bird Families of The World. The Megapodes. Oxford University Press.

Lembang, R. K., Sunarno, O. F. W. Tutupary, B. R. Toisutta, and B.A Sadjab. 2018. Konservasi Burung Gosong Maluku (Eulipoa Wallacei) Berbasis Masyarakat Di Desa Simau, Kecamatan Galela. Jurnal Hutan Pulau-Pulau Kecil 2(2): 195-200.

Pertiwi, P. K, D. Ristiana, N. Isnaini, G. Prajitno. 2015. Uji konduktivitas Termal Pada Interaksi Dua Logam Besi (Fe) Dengan Variasi Bahan Berbentuk Silinder, Jurnal Fisika Laboratorium Lab. Material 2015 Hal. 1-4. Institut Teknologi Sepuluh Nopember (ITS) Surabaya.

Sapsuha, Y., N. Sjafani, N. Albaar, and H. Ishak. 2017. Karakteristik Sarang dan Penetasan Telur Burung Mamoa (Eulipoa wallecei) di Galela Kabupaten Halmahera Utara, Jurnal Agripet 17(1): 38-42.

Sjafani, N. 2006. Study on the Development of Embryo of Moluccan Scrub fowl in Galela Sub district North Halmahera Regency. Thesis. Post Gradute Program. IPB.

Bogor. 
Sjafani, N., L. Hakim, Nurgi artiningsih V.M.A, Suyadi. 2015. The habitat and Estimation population of mama bird (Eulipia Wallacei) in Galela-Halmahera. Journal of Biodiversity and Environmental Sciences. 7(2):1-9.
Sujatnika, P. Jepson, T.R. Soerhartono, M. J. Crocby, dan A. Mardiastuti. 1995. Melestarikan Keanekaragaman Hayati Indonesia : Pendekatan Daerah Endemik. BirdLife Internasional Indonesia Program. Bogor. 